
3 Research Square
Preprints are preliminary reports that have not undergone peer review.
They should not be considered conclusive, used to inform clinical practice,
or referenced by the media as validated information.

\title{
Role of hippocampal location and radiation dose in glioblastoma patients with hippocampal atrophy
}

\author{
Clara Le Fèvre ( $\Delta$ c.lefevre@icans.eu ) \\ ICANS https://orcid.org/0000-0002-5340-5437 \\ Xue Cheng \\ Chongqing Three Gorges University \\ Marie-Pierre Loit \\ Hautepierre Hospital Department of Neurosurgery: Hopital de Hautepierre Service de Neurochirurgie \\ Audrey Keller \\ ICANS \\ Hélène Cebula \\ Hautepierre Hospital Department of Neurosurgery: Hopital de Hautepierre Service de Neurochirurgie \\ Delphine Antoni \\ ICANS \\ Alicia Thiery \\ ICANS \\ Jean-Marc Constans \\ CHU Amiens-Picardie: Centre Hospitalier Universitaire Amiens-Picardie \\ François Proust \\ Hautepierre Hospital Department of Neurosurgery: Hopital de Hautepierre Service de Neurochirurgie \\ Georges Noel \\ ICANS
}

\section{Research Article}

Keywords: hippocampus, volume, dose effect, glioblastoma

Posted Date: April 6th, 2021

DOI: https://doi.org/10.21203/rs.3.rs-367258/v1

License: () This work is licensed under a Creative Commons Attribution 4.0 International License. Read Full License 


\section{Abstract}

Background The hippocampus is a critical organ for irradiation. Thus, we explored changes in hippocampal volume according to the dose delivered and the location relative to the glioblastoma.

Methods All patients were treated for glioblastoma with surgery, concomitant radiotherapy and temozolomide, and adjuvant temozolomide. Hippocampi were retrospectively delineated on three MRIs, performed at baseline, at the time of relapse, and on the last MRI available at the end of follow-up. A total of 98,96 , and 82 hippocampi were measured in the 49 patients included in the study, respectively. The patients were stratified into three subgroups according to the dose delivered to $40 \%$ of the hippocampus. In the group $1(n=6)$, the hippocampal $D_{40 \%}$ was $<7.4 \mathrm{~Gy}$, in the group 2 $(n=13)$, only the $H_{\text {contra }} D_{40 \%}$ was $<7.4 \mathrm{~Gy}$, and in the group $3(n=30)$, the $D_{40 \%}$ for both hippocampi was $>7.4 \mathrm{~Gy}$.

Results Regardless of the time of measurement, homolateral hippocampal volumes were significantly lower than those contralateral to the tumor. Regardless of the side, the volumes at the last MRI were significantly lower than those measured at baseline. There was a significant correlation among the decrease in hippocampal volume regardless of its side, and $D_{\max }(p=0.001), D_{98 \%}(p=0.028)$ and $D_{40 \%}(p=0.0002)$. After adjustment for the time of MRI, these correlations remained significant. According to the $\mathrm{D}_{40 \%}$ and volume at $\mathrm{MRI}_{\text {last }}$, the hippocampi decreased by $4 \mathrm{~mm}^{3} / \mathrm{Gy}$ overall.

Conclusions There was a significant relationship between the radiotherapy dose and decrease in hippocampal volume. However, at the lowest doses, the hippocampi seem to exhibit an adaptive increase in their volume, which could indicate a plasticity effect. Consequently, shielding at least one hippocampus by delivering the lowest possible dose is recommended so that cognitive function can be preserved.

Trial registration: Retrospectively registered.

\section{Introduction}

New memories was associated with neural stem cells located in the subgranular zone of the hippocampal dentate gyrus [1]. Injury of these cells has been hypothesized to be one of the leading causes of the radiation-induced early cognitive decline [2]. Preclinical studies have shown that low doses of radiotherapy are sufficient to induce a decrease in neurogenesis in the subgranular zone. This loss in neurogenic capacity is reportedly correlated with a decline in new memory formation and impaired recall [3]. Furthermore, clinical trials have demonstrated the validity of these preclinical results by dosimetric analysis [4, 5]. Fortunately, new radiotherapy techniques, such intensity-modulated radiation therapy (IMRT), have helped to protect hippocampi and prevent cognitive decline [6-8].

According to trials investigating brain metastasis, dose constraints have been described for both hippocampi [5, 8]. In the setting of partial-brain irradiation, there has also been evidence indicating that a higher radiotherapy (RT) dose to the hippocampus may be associated with greater memory impairment $[4,9,10]$.

Trials studying hippocampal shielding and cognitive consequences have mainly been designed for and conducted in patients with whole-brain irradiation or stereotactic irradiation of multiple metastases leading to an equivalent dose in both hippocampi $[5,7,8]$. In glioma, the radiation fields were mainly asymmetrical, allowing for one hippocampus to be shielded.

Hippocampal volume tracking with structural MRI has proven clinical utility in a variety of diseases, including Alzheimer's disease [11, 12], temporal lobe epilepsy [13], and traumatic brain injury [14]. Interestingly, Maguire et al. showed that taxi drivers' hippocampi were larger than those of other people, which was not correlated with innate navigational expertise but with training and their ability to use their spatial knowledge [15, 16].

Many authors have investigated the role of hippocampal and memory disorders in numerous pathologies [9, 13, 17-21]. Thus, complementary studies on the consequences of hippocampal irradiation are warranted to improve memory preservation in brain radiotherapy patients.

The purpose of the study was to evaluate changes in hippocampus size among irradiated glioblastoma (GBM) patients during the follow-up according to the tumor side and the received dose and to assess whether the changes to the nonirradiated/low-irradiated hippocampus are similar to those of the higher-irradiated hippocampus.

\section{Methods}

The institutional review board approved this retrospective study. All patients gave their consent to collect and analyze their data, and all live patients specifically agreed to participate in this study, according to the French CNIL law MR004.

Forty-nine patients with GBM, treated with irradiation, were retrospectively analyzed in this study. There were 34 males and 15 females with a median age of 61-years old (mean: 60.6; min-max: 24-81). Twenty-five tumors were located in the left cerebral hemisphere, and 24 were located in the right cerebral hemisphere.

Imaging acquisition

Page 2/12 
All MR images were acquired using a Signa Excite HDx 3.T ${ }^{\mathrm{TM}}$ system (GE Healthcare, Milwaukee, WI) with an 8-channel dedicated head coil. The MRI scanning protocol included pre- and postcontrast 1-mm, 3-dimensional (3D) volumetric T1-weighted multiecho magnetization-prepared rapidacquisition gradient echo (MPRAGE) images, and 3D T2-weighted fluid-attenuated inversion recovery (FLAIR) images. Three MRI image sets were analyzed. The first MRI was obtained with a median interval of 13 days (mean 12,7; min-max: 5-23) before the start of RT (MRI dosimetric), the second at the time of relapse $\left(\mathrm{MRI}_{\text {relapse }}\right.$ ), with a median interval of 4.6 months (mean 7.2; min-max: 1.1-22.0) after the end of RT, and the third was the last MRI during follow-up ( $\mathrm{MRI}_{\text {last }}$ ), with a median interval of 17.6 months (mean 17.7; min-max: 3.3-44.3) after the end of RT. The median time interval between $\mathrm{MRI}_{\text {relapse }}$ and $\mathrm{MRI}_{\text {last }}$ was 11.4 months (mean 13;1; 1.9-36.7).

The Planning Target Volume (PTV) included tumors visualized on a gadolinium-enhanced T1 weighted MPRAGE sequence plus a 10 mm-margin completed with edema in the FLAIR sequence, finally encompassed by a 3-mm margin. GBM patients were irradiated at a dose of 60 Gy in 30 daily fractions of $2 \mathrm{~Gy}$, five days a week. All the patients received concomitant chemotherapy with temozolomide at a median daily dose of 140 mg (mean 135.85; min-max:120-160). Forty-three patients underwent a median number of 6 cycles (1-10) of adjuvant chemotherapy at a median daily dose of $340 \mathrm{mg}$ (mean 330; 140-400) according to the EORTC/NCIC protocol [22].

\section{Hippocampus delineation}

Hippocampi were prospectively delineated on the gadolinium-enhanced T1-weighted MPRAGE sequence with 1-mm slices MRI dosimetric and retrospectively delineated from the same MRI sequence on the $\mathrm{MRI}_{\text {relapse, }}$ and the $\mathrm{MRI}_{\text {last }}$, according to atlas $[6,23]$. Hippocampal delineation was performed by a radiation oncologist with a five years of experience $(x x)$ and approved by a radiation oncologist (xx) with over 20 years of experience [24].

Hippocampi were not included if there was any distortion in the hippocampal anatomy due to postsurgical effects or proximity/invasion of the tumor. Hippocampal volumes were stratified into contralateral $\left(\mathrm{H}_{\text {contra }}\right)$ and homolateral $\left(\mathrm{H}_{\text {homo }}\right)$ to the GBM, and the composite bilateral consisted of the sum of $\mathrm{H}_{\text {contra }}$ and $\mathrm{H}_{\text {homo }}\left(\mathrm{H}_{\text {sum }}\right)$. At baseline $\mathrm{MRI}_{\text {dosimetric, }} \mathrm{MRI}_{\text {relapse, }}$ and $\mathrm{MRI} \mathrm{l}_{\text {last }}$, the numbers of delineated hippocampi were 98, 96, and 82, respectively. No patient had both hippocampi censored.

\section{Scheduled doses to hippocampi}

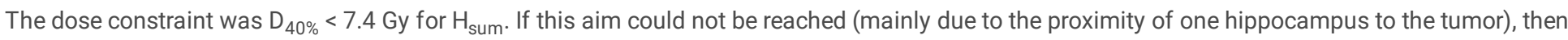
this constraint was imposed on the contralateral hippocampus. In the case of cross-median line GBM, the planning tried to reach the lowest dose as possible in the $\mathrm{H}_{\text {contra. }}$. However, hippocampal constraint respect was never preferred to the tumor coverage (D98\% > 95\% of the prescribed dose) to limit the risk of GBM relapse.

Finally, the entire patient group was split into three subgroups according to the dose delivered to $40 \%$ of the hippocampus. In group 1 ( $n=6$ ), the hippocampal $D_{40 \%}$ was $<7.4 \mathrm{~Gy}$, in group $2(n=13)$, only $H_{\text {contra }} D_{40 \%}$ was $<7.4 \mathrm{~Gy}$, and in group $3(n=30)$, both hippocampal $D_{40 \%}$ were $>7.4 \mathrm{~Gy}$. Furthermore, hippocampi were split into four subgroups according to the $\mathrm{D}_{40 \%},<7.4 \mathrm{~Gy}$, between $7.4 \mathrm{~Gy}$ and $<30 \mathrm{~Gy}$, between $\geq 30 \mathrm{~Gy}$ and $<50 \mathrm{~Gy}$, and $\geq 50$ Gy.

\section{Statistics}

Volumes of hippocampi were determined on MRI dosimetric $\left(\mathrm{H}_{\text {homo-j0 }}, \mathrm{H}_{\text {contra-j0, }}\right.$ and $\left.\mathrm{H}_{\text {sum-j0 } 0}\right)$, on MRI $\mathrm{Melapse}_{\text {remo-relapse, }}\left(\mathrm{H}_{\text {contra-relapse, }}\right.$, and $\left.\mathrm{H}_{\text {sum-relapse }}\right)$, and $\mathrm{MRI}_{\text {last }}\left(\mathrm{H}_{\text {homo-last }}, \mathrm{H}_{\text {contra-last, }}\right.$ and $\left.\mathrm{H}_{\text {sum-last }}\right)$.

The minimum dose $\left(\mathrm{D}_{\min }\right)$, mean dose $(\bar{D})$, maximum dose $\left(\mathrm{D}_{\max }\right), \mathrm{D}_{2} \%, \mathrm{D}_{10 \%}, \mathrm{D}_{40 \%}, \mathrm{D}_{50 \%}, \mathrm{D}_{80} \%$, and $\mathrm{D}_{98 \%} \%$ were collected for each hippocampus and for the combination of both. According to the linear-quadratic model, for the hippocampi receiving less than $2 \mathrm{~Gy}$ per fraction, doses were recalculated with an $\alpha / \beta=2 \mathrm{~Gy}$. The change in hippocampal volumes was analyzed according to the doses, follow-up time, and contact/proximity to the GBM using Pearson's productmoment correlation. Comparisons of the distribution of volumes, doses, and percentages between homolateral and contralateral hippocampus were performed with the T.Test. RStudio Version 1.2.5033 was used to perform statistical calculations.

\section{Results}


The volumes are presented in table 1. Regardless of the time of measurement, the volume of $\mathrm{H}_{\text {homo }}$ was always significantly lower than those of

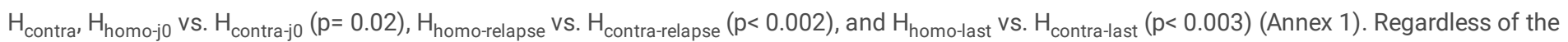
side, the volume at the last measurement was always significantly lower than that measured at baseline, $H_{\text {homo-j0 }}$ vs. $H_{\text {homo-last }}(p=0.02), H_{\text {contra-jo }} v s$. $\mathrm{H}_{\text {contra-last }}(\mathrm{p}=0.049)$. There was no significant difference in the measurements between $\mathrm{MRI}_{\text {relapse }}$ and $\mathrm{MRI}_{\text {last }}$, neither for $\mathrm{H}_{\text {homo }}$ nor $\mathrm{H}_{\text {contra }}(A n n e x$ 1a).

\section{Group stratification}

The volumes are presented in table 2. According to intragroup comparisons, only for group 3 was the volume of $\mathrm{H}_{\text {homo-G3 }}$ always lower than those of $H_{\text {contra-G3 }}, H_{\text {homo-j0-G3 }}$ vs. $H_{\text {contra-j0-G3 }}(p=0.01), H_{\text {homo-relapse-G3 }}$ vs. $H_{\text {contra-relapse-G3 }}(p=0.01)$, and $H_{\text {homo-last-G3 }}$ vs. $H_{\text {contra-last-G3 }}(p=0.01)($ Annex $2 a)$.

According to intergroup analysis, significant decreases in volume were observed between $G 1$ and $G 3$ for $H_{\text {homo-j0-G1 }}$ vs $H_{\text {homo-j0-G3 }}(p=0.03)$, $H_{\text {homo- }}$ relapse-G1 vs $H_{\text {homo-relapse-G3 }}(p=0.02), H_{\text {homo-last-G1 }}$ vs $H_{\text {homo-last-G3 }}(p=0.01)$ and $H_{\text {contra-last-G1 }}$ vs $H_{\text {contra-last-G3 }}(p<0.01)$. There was no significant difference in volume between G1 and G2 and between G2 and G3 (Annex 2a).

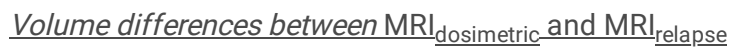

Overall patients (table 1)

For $\mathrm{H}_{\text {homo, }}$, the median volume of reduction was $-310 \mathrm{~mm}^{3}$ corresponding to a difference of $-9.5 \%,(p=0.02$ and $p=0.02$, respectively) (Annex $1 \mathrm{~b})$. For $H_{\text {contra }}$, the median volume of reduction was $-140 \mathrm{~mm}^{3}$ corresponding to a difference of $-3.97 \%(p=0.02$ and $p=0.02$, respectively) (Annex $1 b)$.

\section{Group stratification (table 2)}

According to intra- or inter-group analysis, no significant differences were observed (Annex 2b, 2c).

$\underline{\text { Volume differences between } \mathrm{MRI}} \underline{\underline{\text { dosimetric }}} \underline{\text { and } \mathrm{MRI}} \underline{\underline{\text { last }}}$

Overall patients (table 1)

For $\mathrm{H}_{\text {homo, }}$, the median volume of reduction was $-520 \mathrm{~mm}^{3}$, representing a difference of $-17.6 \%(p=0.03$ and $p=0.01$, respectively) (Annex $1 \mathrm{~b})$. For $H_{\text {contra }}$, the median volume of reduction was $-190 \mathrm{~mm}^{3}$, representing a difference of $-5.37 \%(p=0.03$ and $p=0.01$, respectively) (Annex $1 b)$.

\section{Group stratification (table 2)}

According to intragroup analysis, differences were only significant for $\mathrm{H}_{\text {contra-dosi-G3 }} v_{\text {s }} \mathrm{H}_{\text {contra-last-G3} \text {, and their median volumes were } 3640 \text { mm }}{ }^{3}$ and $3310 \mathrm{~mm}^{3}(p=0.18)$ (Annex $\left.2 b\right)$, representing a difference of $-5.37 \%(p=0.03)$ (Annex $\left.2 c\right)$. According to intergroup analysis, no significant difference was observed.

$\underline{\text { Volume difference between } \mathrm{MRI}} \underline{\text { relapse }}_{\text {and } \mathrm{MRI}} \underline{\text { last }}$

Overall Patients (Table 1)

For $\mathrm{H}_{\text {homo }}$ and $\mathrm{H}_{\text {contra }}$, volume reduction was not significantly different (Annex $1 \mathrm{~b}$ ).

Group stratification (table 2)

According to intra- or intergroup analysis, no significant differences were observed (Annex 2b, 2c).

\section{$\underline{\text { Dose distribution and volume }}$}

Overall patients (table 3a)

On both sides, the volume decrease at $M R I_{\text {last }}$ time was correlated with $\mathrm{D}_{\text {max }}, \mathrm{D}_{98 \%}$ and $\mathrm{D}_{40 \%}(\mathrm{p}=0.0011, \mathrm{p}<0.001$ and $p=0.0002$, respectively).

For $D_{\min }, D_{2 \%}, D_{\max }, D_{98 \%}, D_{10 \%}, D_{40 \%}, D_{50 \%}, D_{80 \%}$, and $D_{100 \%}$, the values for $H_{\text {homo }}$ were significantly higher than those for $H_{\text {contra }}(p<0.0001$ for all comparisons)

Before and after recalculation with a 2-Gy equivalent-dose, each analyzed dose value was significantly higher for $\mathrm{H}_{\text {homo }}$ than for $\mathrm{H}_{\text {contra }}(\mathrm{p}<0.0001$ for all comparisons). 


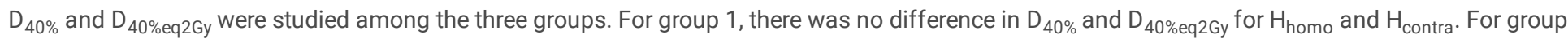
2, the median $\mathrm{D}_{40 \%}$ and $\mathrm{D}_{40 \% \text { eq2 }}$ values were significantly higher in $\mathrm{H}_{\text {homo }}$ than in $\mathrm{H}_{\text {contra, }} 38.5$ Gy vs $5.1 \mathrm{~Gy}(\mathrm{p}<0.001)$ and $31.6 \mathrm{~Gy}$ and $2.8 \mathrm{~Gy}(\mathrm{p}<$ $0.0001)$, respectively. For group 3, comparable differences were observed for 59.3 Gy vs 18.5 Gy ( $<<0.001)$ and 58.9 Gy vs. $12.1 \mathrm{~Gy}$ ( $p<0.0001)$, respectively.

\section{Correlation between hippocampus volumes and dose}

Overall patients (table 4)

There was a significant correlation between the decrease in the volume of the hippocampus, regardless of its side and $D_{\text {max }}(p=0.001)$, $D_{98 \%}(p=$ $0.028)$ and $D_{40 \%}(p=0.0002)$. Adjusted to the time of analysis, these correlations remained significant. According to $D_{40 \%}$ and volume at $M R I_{\text {last }}$ time, overall hippocampi decreased by $4 \mathrm{~mm}^{3} / \mathrm{Gy}$. However, these changes were not linear when the doses were stratified into four subgroups, $<7.4 \mathrm{~Gy}$, between $7.4 \mathrm{~Gy}$ and $<30 \mathrm{~Gy}$, between ${ }^{3} 30 \mathrm{~Gy}$ and $<50 \mathrm{~Gy}$, and ${ }^{3} 50 \mathrm{~Gy}$. The slopes were $+94.3 \mathrm{~mm}^{3} / \mathrm{Gy},-8.6 \mathrm{~mm}^{3} / \mathrm{Gy},-44.5 \mathrm{~mm}^{3} / \mathrm{Gy}, \mathrm{and}^{-112.2}$ $\mathrm{mm}^{3} /$ Gy, respectively.

\section{Group stratification (table 5)}

For group 1 , the change in volume for $\mathrm{H}_{\text {homo }}$ and $\mathrm{H}_{\text {contra }}$ from $\mathrm{MRI}_{\text {dosimetric }}$ to $\mathrm{MRI}_{\text {last }}$, according to $\mathrm{D}_{40 \%}$, was opposite, with slopes of $-124 \mathrm{~mm} / \mathrm{Gy}$ and $+172 \mathrm{~mm}^{3} /$ Gy, respectively.

For group 2, $\mathrm{H}_{\text {homo }}$ and Hcontra's evolution was also opposite, $-15 \mathrm{~mm}^{3} / \mathrm{Gy}$ and $+154 \mathrm{~mm}^{3} /$ Gy, respectively.

For group 3 , the slopes of the change in volume for $\mathrm{H}_{\text {homo }}$ and $\mathrm{H}_{\text {contra }}$ volumes followed the same directions, with $-19.7 \mathrm{~mm}{ }^{3} / \mathrm{Gy}$ and $-19.7 \mathrm{~mm}^{3} / \mathrm{Gy}$, respectively.

\section{Discussion}

The dose constraints of hippocampi are currently well defined to dramatically and efficiently decrease the hippocampal dose and, consequently, memory impairment. However, these dose constraints were primarily referenced by $D_{40 \%}$, including both hippocampi, and were proposed secondary to the results of the first study, which used whole-brain radiation therapy, where hippocampi were irradiated or shielded symmetrically. In contrast, only two studies have focused on asymmetric irradiation in glioma [4, 25].

To our knowledge, this is the first study to investigate $\mathrm{D}_{40 \%}$ in hippocampal volumes measured by MRI and to analyze the change in the hippocampus contralateral to the GBM after irradiation. This study clearly showed that the volume of hippocampi decreased after radiotherapy in patients irradiated for GBM. However, the decrease in hippocampal size depended on the tumor side and relied on the received radiation dose. These factors could explain the variability in memory disturbances after brain irradiation.

Delineation of hippocampi, which requires training and support of the atlas, have been recommended [6, 23]. In the study by Gondi et al., for protection, hippocampi were manually delineated according to the protocol but only after the planning dose calculation was determined [4]. Notably, Siebert et al. used an automated segmentation method that is more reproducible than manual tracing that requires more expertise and training. Furthermore, in the Siebert et al studies, all images were obtained with the same MRI devices, which required conditions to optimize the automated delineation that often deviated from daily practice [26-28]. Computerized segmentation volume methods were shown to be competitive with expert segmentation [17]. The main advantage of automated processes is the decrease in interobserver variability. However, automatic segmentation methods have enabled the subevaluation of hippocampal atrophy that develops over time [29]. In the present study, only one radiation oncologist delineated all the hippocampi, which improved the quality of volume comparison and removed the interobserver variability.

In this study, the median volumes of the homolateral and the contralateral hippocampi were $3400 \mathrm{~mm}^{3}$ and $3540 \mathrm{~mm}^{3}$, respectively. These volumes compared favorably with the measurement obtained by Gondi et al. in their delineation study, at $3300 \mathrm{~mm}^{3}\left(\mathrm{range}_{2} 2800-4000 \mathrm{~mm}^{3}\right)$ [6].

Physiologically, the decreasing hippocampi volume in one year was between $0.8 \%$ and $4.4 \%$ of the initial volume [30]. In a meta-analysis, the hippocampus atrophy rates in the both hippocampus, the left hippocampus, and the right hippocampus were $0.85 \%, 0.64 \%$, and $0.70 \%$, respectively. For both hippocampi, the atrophy rate differed according to the age and was $0.38 \%, 0.98 \%$, and $1.12 \%$ in patients younger tnan 50 , between 50 and 70, and older than 70, respectively [31]. In contrast, Prust et al. did not observe any change in the nine-month MRI-follow-up in 14 patients treated for GBM [32]. The median decrease in hippocampal volumes varied from 4-17.6\% in the current series, depending on the tumor side, received dose, and time after irradiation.

Gondi et al. did not show any correlation with the hippocampus analyzed separately [4]. Moreover, the authors analyzed the hippocampus dose on the left and right hemispheres but not according to their position in terms of the tumor side. The results of the current study showed that the hippocampal 
volume decrease is dependent on location of the hippocampus relative to the tumor. At the time of relapse, the percent decrease in volume was more substantial in the homolateral hippocampus than in the contralateral hippocampus, at $10.3 \%$ and $4 \%$, respectively. These values increased over time and were $17.6 \%$ and $5.4 \%$ at the last follow-up MRI with no significant size difference observed between MRI relapse and MRI last. This demonstrated a clear relationship between the post-irradiation time and hippocampal atrophy, with substantial changes appearing in the first months after RT. In the case series reported by Siebert et al., the authors did not include the volume of hippocampi close to the tumor and did not compare the volume in terms of adaptation [25]. In this work, we showed that the median volume of the homolateral hippocampi relative to the glioblastoma was always lower that of the contralateral hippocampi. The impact of glioblastoma on hippocampi functioning and homeostasis is unknown, but these results suggest an interaction. However, the consequences of surgery always being performed before the reference MRI (MRI $\mathrm{dosimetry}$ ) cannot be excluded, but other causes should also be considered (medicine, age, addiction, estrogen level, corticosteroid intake...) [33]. Another assumed reason to explain this difference is the possible ability of the contralateral hippocampus to compensate for the decrease in the homolateral hippocampus volume after a low dose of irradiation, as a plasticity effect has already been shown in some variable situations [18, 20, 34].

Animal studies have shown that when the brains of young rats are unilaterally irradiated, the volume of the irradiated hippocampus is reduced compared to that of the nonirradiated side, corresponding to apoptosis, which induces the loss of neural stem cells and progenitor cell proliferation $[35,36]$. A postmortem study on patients treated with chemotherapy and cranial irradiation showed profoundly reduced hippocampal neurogenesis. This observation further supports the hypothesis that neurocognitive impairment after brain-directed therapy hampers hippocampal neurogenesis to some degree $[37,38]$. In the study by Gondi et al., doses to the tumor were variable, and the fractionation differed according to the nature of the tumor, varying from 1.8 to 4 Gy per fraction. After cognitive tests, among the 29 patients, $12.5 \%$ presented changes in their performance on the WMS-III Word Lists Delayed Recall Test. Risk impairment was significantly correlated with a $D_{40 \%}$ in the bilateral hippocampi $>7.4 \mathrm{~Gy}(p=0.043)$ [4].

Seibert et al. included 52 patients and 79 noninvaded or nonchanged hippocampi because of surgery or the tumor's proximity. Hippocampal volume loss was significantly correlated with the mean RT dose delivered to the hippocampus $(p=0.03)$. The mean hippocampal volume was significantly reduced one year after high-dose (>40 Gy) radiation therapy, but not after low-dose (<10 Gy) radiation therapy [25]. In the current study, there was a correlation between the delivered $D_{\text {max }}, D_{98 \%}$, and $D_{40 \%}$ with decreasing hippocampal volume. Furthermore, we showed that the volume decreased continuously with $\mathrm{D}_{40 \%}$ from $>7.5 \mathrm{~Gy}$ to $>50 \mathrm{~Gy}$. Notably, for $\mathrm{D}_{40 \%}<7.4 \mathrm{~Gy}$, hippocampal volumes increased. Dose-dependent brain changes were also demonstrated for white matter [39], the amygdala [40], and left-sided perisylvian white matter [41]. In our study, the hippocampi receiving less than 7.4 Gy were always contralateral hippocampus relative to the GBM, and in 7 cases, the homolateral hippocampus whom $D_{40 \%}$ was $<7.4$ Gy because the GBM was far enough away from the hippocampus and consequently, the hippocampus was not in, or near the radiation fields.

Finally, Siebert et al. included patients treated with nonclassical doses (1.8-2 Gy per fraction) and tried to calculate the dose equivalent to compare the results obtained with the different fractionations used [25]. At one year, atrophy in the hippocampi that received a dose $>40 \mathrm{~Gy}$ was $6 \%$, which represented a relevant value compared to the $1 \%$ volume loss per year observed in the elderly [30, 31 ] and the 2.2 to $4 \%$ volume loss per year observed in Alzheimer's patients with mild to severe cognitive decline [29, 30, 42]. For the entire series, we noted a median decrease of $0.33 \%$ in hippocampal volumes over a median period of 17.5 months (time between $\mathrm{MRI}_{\text {dosimetry }}$ and $\mathrm{MRI}_{\text {last }}$ ), but a median reduction of $5.55 \%$ in hippocampi that received more than 50 Gy in the same period.

In the study by Seibert et al., no significant hippocampal atrophy was detected after low-dose radiation treatment (mean < 10 Gy) exposure [25]. These findings were consistent with a previous study of 15 patients with head and neck malignancy, where a low incidental radiation dose to the hippocampus did not result in hippocampal volume loss [27]. Similarly, a study of 14 GBM patients reported no volume change six months after the start of chemoradiotherapy [32]. A phase II trial investigating hippocampal protection in the whole-brain radiation therapy setting (30 Gy in 10 fractions, RTOG 0933) found less short-term memory impairment than historical controls when constraining the mean dose to the hippocampus to less than $10 \mathrm{~Gy}$ [5]. In the study by Maguire et al., taxi drivers had a significantly higher volume in the posterior hippocampus, whereas control subjects showed a higher volume in the anterior hippocampus [42]. The ratio between posterior and anterior hippocampal volumes seems to be correlated with the cognitive mapping [43]. In our current series, contralateral hippocampi that received a $\mathrm{D}_{40 \%}$ less than $7.4 \mathrm{~Gy}$ did not show any atrophy in the hippocampus; in contrast the volume increased significantly. Physiological and functional compensations could explain this observation, but methods to specifically study each hippocampus separately have not yet been developed. At present, our study cannot confirm that when the dose of irradiation was low, the increased volume was an adaptive reaction to irradiation or a natural adaptation to the brain trauma.

Notably, regardless of the tumor distance, the homolateral hippocampus volume was always significantly smaller than the contralateral hippocampus volume. This relative atrophy suggested that dose was not the sole cause of this decline. Other causes could be vascular disruption and permeability [21], alteration of interneurons [19], and neuroinflammation [39]. This difference in hippocampal volume has already been described in hippocampal sclerosis and epilepsy $[13,17,29,30]$. However, it is unknown whatever this difference in volume was due to a variation secondary to atrophy alone (i.e., the contralateral hippocampus having a normal volume) or atrophy and unaltered volume compensation in the contralateral hippocampus [24]

This study was limited by the absence of specific cognitive performance measures to correlate with the observed structural neuroimaging changes. Validated cognitive tests are not always used in routine clinical practice, precluding clinical neurologic observation analysis in retrospective studies. However, these tests should be precise and split the left or right hippocampus [44], and dose thresholds should be relevantly chosen [45] to avoid unclear or confusing analysis. Moreover, advanced imaging access is still limited in medical practice, and other brain regions are involved in cognitive 
functions $[39,46]$. Another drawback is the lack of a control group to measure the change in the hippocampus over time in a population based on age, $\mathrm{IK}, \ldots$. However, this requirement could be disputed because of the absence of tumors, which probably interact with the hippocampal structure through the microenvironment. To correlate neurocognitive outcomes with structural brain changes, prospective longitudinal trials are needed to examine performance in multiple cognitive domains in concert with serial neuroimaging [47].

\section{Conclusion}

This study demonstrated a $D_{40 \%}$-dependent atrophy effect on the irradiated hippocampus. The volume of the contralateral hippocampus increased when irradiated at a $\mathrm{D}_{40 \%}<7.4 \mathrm{~Gy}$ increased, suggesting a compensatory reaction. Thus, limiting the radiation dose to the greatest extent possible in at least one hippocampus is recommended, when relevant, in cases of asymmetrical brain cancer.

\section{List Of Abbreviations}

FLAIR: Fluid-attenuated inversion recovery

GBM: Glioblastoma

IMRT: Intensity-modulated radiation therapy

MPRAGE: Multiecho magnetization-prepared rapid-acquisition gradient echo

PTV: Planning Target Volume

RT: Radiotherapy

\section{Declarations}

Ethics approval and consent to participate: Data are available as required and authorized by French law MR004.

Consent for publication: Data are available as required and authorized by French law MR004.

Availability of data and materials: The datasets used and/or analyzed during the current study are available from the corresponding author on reasonable request.

Competing interest: The authors declare that they have no competing interests.

Funding: Not applicable.

Authors' contribution:

Clara LE FEVRE: Conceptualization, Methodology, Formal analysis, Investigation, Data curation, Writing-Original draft, Visualization;

Xue CHENG: Formal analysis, Investigation, Data curation, Writing-Original draft, Visualization;

Marie-Pierre LOIT: Validation, Writing-Review and Editing,

Audrey KELLER: Validation, Writing-Review and Editing,

Hélène CEBULA: Validation, Writing-Review and Editing,

Delphine ANTONI: Validation, Writing-Review and Editing,

Alicia THIERY: Sofware, Methodology, Formal analysis, Validation, Writing-Review and Editing;

Jean-Marc CONSTANS: Methodology, Validation, Writing-Review and Editing, Supervision;

François PROUST: Methodology, Validation, Writing-Review and Editing, Supervision;

Georges NOEL: Conceptualization, Methodology, Validation, Writing-Review and Editing, Resources, Supervision, Project administration. Acknowledgements: Not applicable

\section{References}


2 Gondi V., Tome W. A.Mehta M. P. Why avoid the hippocampus? A comprehensive review. Radiother Oncol. 2010; 97: 370-6 10.1016/j.radonc.2010.09.013

3 Monje M. L., Mizumatsu S., Fike J. R.Palmer T. D. Irradiation induces neural precursor-cell dysfunction. Nat Med. 2002; 8: 955-62 $10.1038 / \mathrm{nm} 749$

4 Gondi V., Hermann B. P., Mehta M. P.Tome W. A. Hippocampal dosimetry predicts neurocognitive function impairment after fractionated stereotactic radiotherapy for benign or low-grade adult brain tumors. Int J Radiat Oncol Biol Phys. 2013; 85: 348-54 - 10.1016/j.ijrobp.2012.11.031

5 Gondi V., Pugh S. L., Tome W. A., Caine C., Corn B., Kanner A., et al. Preservation of memory with conformal avoidance of the hippocampal neural stem-cell compartment during whole-brain radiotherapy for brain metastases (RTOG 0933): a phase II multi-institutional trial. J Clin Oncol. 2014; 32: 3810-6 - 10.1200/JC0.2014.57.2909

6 Gondi V., Tolakanahalli R., Mehta M. P., Tewatia D., Rowley H., Kuo J. S., et al. Hippocampal-sparing whole-brain radiotherapy: a "how-to" technique using helical tomotherapy and linear accelerator-based intensity-modulated radiotherapy. Int J Radiat Oncol Biol Phys. 2010; 78: 1244-52 10.1016/j.ijrobp.2010.01.039

7 Hsu F., Carolan H., Nichol A., Cao F., Nuraney N., Lee R., et al. Whole brain radiotherapy with hippocampal avoidance and simultaneous integrated boost for 1-3 brain metastases: a feasibility study using volumetric modulated arc therapy. Int J Radiat Oncol Biol Phys. 2010; 76: 1480-5 10.1016/j.ijrobp.2009.03.032

8 Tsai P. F., Yang C. C., Chuang C. C., Huang T. Y., Wu Y. M., Pai P. C., et al. Hippocampal dosimetry correlates with the change in neurocognitive function after hippocampal sparing during whole brain radiotherapy: a prospective study. Radiat Oncol. 2015; 10: 253 - 10.1186/s13014-015-0562-x

9 Farjam R., Pramanik P., Aryal M. P., Srinivasan A., Chapman C. H., Tsien C. I., et al. A Radiation-Induced Hippocampal Vascular Injury Surrogate Marker Predicts Late Neurocognitive Dysfunction. Int J Radiat Oncol Biol Phys. 2015; 93: 908-15 - 10.1016/j.ijrobp.2015.08.014

10 Peiffer A. M., Shi L., Olson J.Brunso-Bechtold J. K. Differential effects of radiation and age on diffusion tensor imaging in rats. Brain Res. 2010; 1351: $23-31$ - 10.1016/j.brainres.2010.06.049

11 Heister D., Brewer J. B., Magda S., Blennow K., McEvoy L. K.Alzheimer's Disease Neuroimaging I. Predicting MCl outcome with clinically available MRI and CSF biomarkers. Neurology. 2011; 77: 1619-28 - 10.1212/WNL.0b013e3182343314

12 Kovacevic S., Rafii M. S., Brewer J. B.Alzheimer's Disease Neuroimaging I. High-throughput, fully automated volumetry for prediction of MMSE and CDR decline in mild cognitive impairment. Alzheimer Dis Assoc Disord. 2009; 23: 139-45 - 10.1097/WAD.0b013e318192e745

13 Farid N., Girard H. M., Kemmotsu N., Smith M. E., Magda S. W., Lim W. Y., et al. Temporal lobe epilepsy: quantitative MR volumetry in detection of hippocampal atrophy. Radiology. 2012; 264: 542-50 - 10.1148/radiol.12112638

14 Brezova V., Moen K. G., Skandsen T., Vik A., Brewer J. B., Salvesen O., et al. Prospective longitudinal MRI study of brain volumes and diffusion changes during the first year after moderate to severe traumatic brain injury. Neuroimage Clin. 2014; 5: 128-40 - 10.1016/j.nicl.2014.03.012

15 Maguire E. A., Spiers H. J., Good C. D., Hartley T., Frackowiak R. S.Burgess N. Navigation expertise and the human hippocampus: a structural brain imaging analysis. Hippocampus. 2003; 13: 250-9 - 10.1002/hipo.10087

16 Maguire E. A., Gadian D. G., Johnsrude I. S., Good C. D., Ashburner J., Frackowiak R. S., et al. Navigation-related structural change in the hippocampi of taxi drivers. Proc Natl Acad Sci U S A. 2000; 97: 4398-403 - 10.1073/pnas.070039597

17 Brewer J. B., Magda S., Airriess C.Smith M. E. Fully-automated quantification of regional brain volumes for improved detection of focal atrophy in Alzheimer disease. AJNR Am J Neuroradiol. 2009; 30: 578-80 - 10.3174/ajnr.A1402

18 Maggio N.Segal M. Corticosteroid regulation of synaptic plasticity in the hippocampus. ScientificWorldJournal. 2010; 10: 462-9 $10.1100 /$ tsw.2010.48

19 Malmgren K.Thom M. Hippocampal sclerosis-origins and imaging. Epilepsia. 2012; 53 Suppl 4: 19-33 - 10.1111/j.1528-1167.2012.03610.x

20 Sheppard P. A. S., Choleris E.Galea L. A. M. Structural plasticity of the hippocampus in response to estrogens in female rodents. Mol Brain. 2019; 12: 22 - 10.1186/s13041-019-0442-7

21 Sun J. H., Tan L.Yu J. T. Post-stroke cognitive impairment: epidemiology, mechanisms and management. Ann Transl Med. $2014 ; 2$ : 80 10.3978/j.issn.2305-5839.2014.08.05

Page 8/12 

temozolomide for glioblastoma. N Engl J Med. 2005; 352: 987-96 - 10.1056/NEJMoa043330

23 Chera B. S., Amdur R. J., Patel P.Mendenhall W. M. A radiation oncologist's guide to contouring the hippocampus. Am J Clin Oncol. 2009; 32 : 20-2 - 10.1097/COC.0b013e318178e4e8

24 Urbach H., Huppertz H. J., Schwarzwald R., Becker A. J., Wagner J., Bahri M. D., et al. Is the type and extent of hippocampal sclerosis measurable on high-resolution MRI? Neuroradiology. 2014; 56: 731-5 - 10.1007/s00234-014-1397-0

25 Seibert T. M., Karunamuni R., Bartsch H., Kaifi S., Krishnan A. P., Dalia Y., et al. Radiation Dose-Dependent Hippocampal Atrophy Detected With Longitudinal Volumetric Magnetic Resonance Imaging. Int J Radiat Oncol Biol Phys. 2017; 97: 263-269 - 10.1016/j.ijrobp.2016.10.035

26 Riggs L., Bouffet E., Laughlin S., Laperriere N., Liu F., Skocic J., et al. Changes to memory structures in children treated for posterior fossa tumors. J Int Neuropsychol Soc. 2014; 20: 168-80 - 10.1017/S135561771300129X

27 Olsson E., Eckerstrom C., Berg G., Borga M., Ekholm S., Johannsson G., et al. Hippocampal volumes in patients exposed to low-dose radiation to the basal brain. A case-control study in long-term survivors from cancer in the head and neck region. Radiat Oncol. 2012; 7: 202 - 10.1186/1748717X-7-202

28 Nagel B. J., Palmer S. L., Reddick W. E., Glass J. O., Helton K. J., Wu S., et al. Abnormal hippocampal development in children with medulloblastoma treated with risk-adapted irradiation. AJNR Am J Neuroradiol. 2004; 25: 1575-82 -

29 Chincarini A., Sensi F., Rei L., Gemme G., Squarcia S., Longo R., et al. Integrating longitudinal information in hippocampal volume measurements for the early detection of Alzheimer's disease. Neuroimage. 2016; 125: 834-847 - 10.1016/j.neuroimage.2015.10.065

30 Schuff N., Woerner N., Boreta L., Kornfield T., Shaw L. M., Trojanowski J. Q., et al. MRI of hippocampal volume loss in early Alzheimer's disease in relation to ApoE genotype and biomarkers. Brain. 2009; 132: 1067-77 - 10.1093/brain/awp007

31 Fraser M. A., Shaw M. E.Cherbuin N. A systematic review and meta-analysis of longitudinal hippocampal atrophy in healthy human ageing. Neuroimage. 2015; 112: 364-374 - 10.1016/j.neuroimage.2015.03.035

32 Prust M. J., Jafari-Khouzani K., Kalpathy-Cramer J., Polaskova P., Batchelor T. T., Gerstner E. R., et al. Standard chemoradiation for glioblastoma results in progressive brain volume loss. Neurology. 2015; 85: 683-91 - 10.1212/WNL.0000000000001861

Kim E. J., Pellman B.Kim J. J. Stress effects on the hippocampus: a critical review. Learn Mem. 2015; 22: 411-6 - 10.1101/Im.037291.114

34 Kutlu M. G.Gould T. J. Effects of drugs of abuse on hippocampal plasticity and hippocampus-dependent learning and memory: contributions to development and maintenance of addiction. Learn Mem. 2016; 23: 515-33 - 10.1101/Im.042192.116

35 Hellstrom N. A., Bjork-Eriksson T., Blomgren K.Kuhn H. G. Differential recovery of neural stem cells in the subventricular zone and dentate gyrus after ionizing radiation. Stem Cells. 2009; 27: 634-41 - 10.1634/stemcells.2008-0732

36 Fukuda A., Fukuda H., Swanpalmer J., Hertzman S., Lannering B., Marky I., et al. Age-dependent sensitivity of the developing brain to irradiation is correlated with the number and vulnerability of progenitor cells. J Neurochem. 2005; 92: 569-84 - 10.1111/j.1471-4159.2004.02894.x

37 Monje M. L., Vogel H., Masek M., Ligon K. L., Fisher P. G.Palmer T. D. Impaired human hippocampal neurogenesis after treatment for central nervous system malignancies. Ann Neurol. 2007; 62: 515-20 - 10.1002/ana.21214

38 Monje M. Cranial radiation therapy and damage to hippocampal neurogenesis. Dev Disabil Res Rev. 2008; 14: 238-42 - 10.1002/ddrr.26

39 Connor M., Karunamuni R., McDonald C., White N., Pettersson N., Moiseenko V., et al. Dose-dependent white matter damage after brain radiotherapy. Radiother Oncol. 2016; 121: 209-216 - 10.1016/j.radonc.2016.10.003

40 Huynh-Le M. P., Karunamuni R., Moiseenko V., Farid N., McDonald C. R., Hattangadi-Gluth J. A., et al. Dose-dependent atrophy of the amygdala after radiotherapy. Radiother Oncol. 2019; 136: 44-49 - 10.1016/j.radonc.2019.03.024

41 Tibbs M. D., Huynh-Le M. P., Karunamuni R., Reyes A., Macari A. C., Tringale K. R., et al. Microstructural injury to left-sided perisylvian white matter predicts language decline after brain radiotherapy. Int J Radiat Oncol Biol Phys. 2020; - 10.1016/j.ijrobp.2020.07.032

42 McEvoy L. K., Holland D., Hagler D. J., Jr., Fennema-Notestine C., Brewer J. B., Dale A. M., et al. Mild cognitive impairment: baseline and longitudinal structural MR imaging measures improve predictive prognosis. Radiology. 2011; 259: 834-43 - 10.1148/radiol.11101975

43 Brunec I. K., Robin J., Patai E. Z., Ozubko J. D., Javadi A. H., Barense M. D., et al. Cognitive mapping style relates to posterior-anterior hippocampal volume ratio. Hippocampus. 2019; - 10.1002/hipo.23072

Page 9/12 
44 Haldbo-Classen L., Amidi A., Lukacova S., Wu L. M., Oettingen G. V., Lassen-Ramshad Y., et al. Cognitive impairment following radiation to hippocampus and other brain structures in adults with primary brain tumours. Radiother Oncol. 2020; 148: 1-7 - 10.1016/j.radonc.2020.03.023

45 Okoukoni C., McTyre E. R., Ayala Peacock D. N., Peiffer A. M., Strowd R., Cramer C., et al. Hippocampal dose volume histogram predicts Hopkins Verbal Learning Test scores after brain irradiation. Adv Radiat Oncol. 2017; 2: 624-629 - 10.1016/j.adro.2017.08.013

46 Connor M., Karunamuni R., McDonald C., Seibert T., White N., Moiseenko V., et al. Regional susceptibility to dose-dependent white matter damage after brain radiotherapy. Radiother Oncol. 2017; 123: 209-217 - 10.1016/j.radonc.2017.04.006

47 Durand T., Jacob S., Lebouil L., Douzane H., Lestaevel P., Rahimian A., et al. EpiBrainRad: an epidemiologic study of the neurotoxicity induced by radiotherapy in high grade glioma patients. BMC Neurol. 2015; 15: 261 - 10.1186/s12883-015-0519-6

\section{Tables}

Table 1: Hippocampi volume, change in volume and percent change according to the interval between MRIs.

\begin{tabular}{|c|c|c|c|c|}
\hline & \multicolumn{3}{|c|}{ Median Volume (min-max) $\mathrm{mm}^{3}$} & \\
\hline & $\mathrm{H}_{\text {homo }}$ & $\mathrm{H}_{\text {contra }}$ & $\mathrm{H}_{\mathrm{sum}}$ & \\
\hline $\mathrm{MRI}_{\text {dosimetric }}$ & $3400(650-4850)$ & $3540(2000-4680)$ & $6940(360$ & $0-9530)$ \\
\hline $\mathrm{MRI}_{\text {relapse }}$ & $3150(610-4630)$ & $3410(2030-4440)$ & $6480(308$ & $30-9050)$ \\
\hline \multirow[t]{3}{*}{$\mathrm{MRI}_{\text {last }}$} & $3060(400-4230)$ & $3350(1860-5780)$ & $6340(324$ & $10-8290)$ \\
\hline & \multicolumn{4}{|c|}{ Median reduction between $\mathrm{MRI}_{\text {dosimetric }}$ and $\mathrm{MRI}_{\text {relapse }}$} \\
\hline & $\mathrm{H}_{\text {homo }}$ & $\mathrm{H}_{\text {contra }}$ & $\mathrm{H}_{\text {sum }}$ & \\
\hline Volume $\left(\mathrm{mm}^{3}\right)$ & $-310(+840--2750)$ & $-140(+500--1160)$ & $-380(+11$ & $70--3460)$ \\
\hline \multirow[t]{3}{*}{$\%$} & $-9.5(+36.0--80.9)$ & $-4.0(+15.9--32.0)$ & $-5.3(+17$. & $9--87.6)$ \\
\hline & \multicolumn{4}{|c|}{ Median reduction between $\mathrm{MRI}_{\text {dosimetric }}$ and $\mathrm{MRI}_{\text {last }}$} \\
\hline & $\mathrm{H}_{\text {homo }}$ & $\mathrm{H}_{\text {contra }}$ & $\mathrm{H}_{\text {sum }}$ & \\
\hline Volume $\left(\mathrm{mm}^{3}\right)$ & $-520(+500--1157)$ & $-190(+1720--201)$ & $-720(+12$ & $00--2310)$ \\
\hline \multirow[t]{3}{*}{$\%$} & $-17.6(+14.7--61.8)$ & $-5.4(+42.4--50.1)$ & $-10.3(+1 \varepsilon$ & $8.3--35.8)$ \\
\hline & \multicolumn{4}{|c|}{ Median reduction between $\mathrm{MRI}_{\text {relapse }}$ and $\mathrm{MRI}_{\text {last }}$} \\
\hline & $\mathrm{H}_{\text {homo }}$ & $\mathrm{H}_{\text {contra }}$ & $\mathrm{H}_{\text {sum }}$ & \\
\hline Volume $\left(\mathrm{mm}^{3}\right)$ & $-150(+960--1470)$ & $-190(+1390--1370)$ & $-290(+14$ & $=0--2230)$ \\
\hline & $-5.0(+25.9--151.5)$ & $-5.7(+32.2--73.7)$ & $-4.2(+18$. & $1--57.0)$ \\
\hline
\end{tabular}

Table 2: Hippocampi volume and change in volume between MRIs according to the D40\% groups.

In group 1 (G1: $\mathrm{n}=6$ ), in both hippocampi, the $\mathrm{D}_{40 \%}$ was $<7.4 \mathrm{~Gy}$; in group 2 (G2: $\mathrm{n}=13$ ), the $\mathrm{H}_{\text {contra }} \mathrm{D}_{40 \%}$ was $<7.4$ Gy; and in group 3 (G3: $n=30)$, the $\mathrm{D}_{40 \%}$ for both hippocampi was $>7.4$ Gy 


\begin{tabular}{|c|c|c|c|c|c|c|}
\hline & \multicolumn{6}{|c|}{ Median Volume (min-max) $\left(\mathrm{mm}^{3}\right)$} \\
\hline & $\mathrm{H}_{\text {homo-G1 }}$ & $\mathrm{H}_{\text {contra-G1 }}$ & $\mathrm{H}_{\text {homo-G2 }}$ & $\mathrm{H}_{\text {contra-G2 }}$ & $\mathrm{H}_{\text {homo-G3 }}$ & $\mathrm{H}_{\text {contra-G3 }}$ \\
\hline $\mathrm{MRI}_{\text {dosimetric }}$ & $\begin{array}{l}3700(3070- \\
4410)\end{array}$ & $3460(2880-$ & $\begin{array}{l}3540(2330- \\
4850)\end{array}$ & $\begin{array}{l}3450(2180- \\
4680)\end{array}$ & $3250(650-4320)$ & $3640(2000-4350)$ \\
\hline $\mathrm{MRI}_{\text {relapse }}$ & $\begin{array}{l}3260(3120- \\
4390)\end{array}$ & $\begin{array}{l}3340(2760- \\
4070)\end{array}$ & $\begin{array}{l}3050(1960- \\
4630)\end{array}$ & $\begin{array}{l}3380(2340- \\
4440)\end{array}$ & $3030(610-3970)$ & $3500(2030-4120)$ \\
\hline \multirow[t]{3}{*}{$\mathrm{MRI}_{\text {last }}$} & $\begin{array}{l}3200(3020- \\
3560)\end{array}$ & $\begin{array}{l}3350(3200- \\
3620)\end{array}$ & $\begin{array}{l}2670(1970- \\
4230)\end{array}$ & $\begin{array}{l}3440(1860- \\
5780)\end{array}$ & $3080(400-3620)$ & $3310(2000-4350)$ \\
\hline & \multicolumn{6}{|c|}{ Median reduction between $\mathrm{MRI}_{\text {dosimetric }}$ and $\mathrm{MRI}_{\text {relapse }}$} \\
\hline & $\mathrm{H}_{\text {homo-G1 }}$ & $\mathrm{H}_{\text {contra-G1 }}$ & $\mathrm{H}_{\text {homo-G2 }}$ & $\mathrm{H}_{\text {contra-G2 }}$ & $\mathrm{H}_{\text {homo-G3 }}$ & $\mathrm{H}_{\text {contra-G3 }}$ \\
\hline $\begin{array}{l}\text { Volume } \\
\left(\mathrm{mm}^{3}\right)\end{array}$ & $\begin{array}{l}-200(+180- \\
-1140)\end{array}$ & $\begin{array}{l}-70(+220- \\
-590)\end{array}$ & $\begin{array}{l}-420(+840- \\
-950)\end{array}$ & $\begin{array}{l}-100(+330- \\
-690)\end{array}$ & $\begin{array}{l}-220(+580- \\
-2750)\end{array}$ & $\begin{array}{l}-220(+500- \\
-1160)\end{array}$ \\
\hline \multirow[t]{3}{*}{$\%$} & $\begin{array}{l}-5.4(+5.5- \\
-26.4)\end{array}$ & $\begin{array}{l}-1.9(+7.6- \\
-17.6)\end{array}$ & $\begin{array}{l}-10.6(+36- \\
-25.9)\end{array}$ & $\begin{array}{l}-3.1(+10.8- \\
-17.8)\end{array}$ & $\begin{array}{l}-8.7(+21.5- \\
-80.9)\end{array}$ & $\begin{array}{l}-5.3(+15.9- \\
-32.0)\end{array}$ \\
\hline & \multicolumn{6}{|c|}{ Median reduction between $\mathrm{MRI}_{\text {relapse }}$ and $\mathrm{MRI}_{\text {last }}$} \\
\hline & $\mathrm{H}_{\text {homo-G1 }}$ & $\mathrm{H}_{\text {contra-G1 }}$ & $\mathrm{H}_{\text {homo-G2 }}$ & $\mathrm{H}_{\text {contra-G2 }}$ & $\mathrm{H}_{\text {homo-G3 }}$ & $\mathrm{H}_{\text {contra-G3 }}$ \\
\hline Volume & $\begin{array}{l}-60(+250- \\
-1370)\end{array}$ & $\begin{array}{l}+10(+100- \\
-500)\end{array}$ & $\begin{array}{l}-150(+960- \\
-970)\end{array}$ & $\begin{array}{l}-20(+1390- \\
-1370)\end{array}$ & $\begin{array}{l}-270(+500- \\
-1470)\end{array}$ & $\begin{array}{l}-210(+1170- \\
-1300)\end{array}$ \\
\hline \multirow[t]{3}{*}{$\frac{(\mathrm{m})}{\%}$} & $\begin{array}{l}-1.7(+7.5- \\
-31.2)\end{array}$ & $\begin{array}{l}+0.3(+3.2- \\
-13.3)\end{array}$ & $-4.8(+35--29.5)$ & $\begin{array}{l}-0.6(+31.7- \\
-42.4)\end{array}$ & $\begin{array}{l}-12.4(+16.0- \\
-60.2)\end{array}$ & $\begin{array}{l}-6.9(+47.6- \\
-39.4)\end{array}$ \\
\hline & \multicolumn{6}{|c|}{ Median reduction between $\mathrm{MRI}_{\text {dosimetric }}$ and $\mathrm{MRI}_{\text {last }}$} \\
\hline & $\mathrm{H}_{\text {homo-G1 }}$ & $\mathrm{H}_{\text {contra-G1 }}$ & $\mathrm{H}_{\text {homo-G2 }}$ & $\mathrm{H}_{\text {contra-G2 }}$ & $\mathrm{H}_{\text {homo-G3 }}$ & $\mathrm{H}_{\text {contra-G3 }}$ \\
\hline $\begin{array}{l}\text { Volume } \\
\left(\mathrm{mm}^{3}\right)\end{array}$ & $\begin{array}{l}-130(+130- \\
-1390)\end{array}$ & $\begin{array}{l}-180(+320- \\
-600)\end{array}$ & $\begin{array}{l}-620(+500- \\
-1400)\end{array}$ & $\begin{array}{l}-190(+1720- \\
-1230)\end{array}$ & $\begin{array}{l}-500(+150- \\
-1570)\end{array}$ & $\begin{array}{l}-190(+840- \\
-2010)\end{array}$ \\
\hline$\%$ & $\begin{array}{l}-3.5(+4.2- \\
-31.5)\end{array}$ & $\begin{array}{l}-5.1(+11.1- \\
-15.5)\end{array}$ & $\begin{array}{l}-20.9(+14.7- \\
-38.1)\end{array}$ & $\begin{array}{l}-5.6(+42.4- \\
-39.8)\end{array}$ & $-17.6(+5--61.8)$ & $\begin{array}{l}-5.4(+23.9- \\
-50.1)\end{array}$ \\
\hline
\end{tabular}

Table 3: Median dose in the hippocampi

Table 3a: Median dose delivered to each hippocampus (homo- or contralateral)

\begin{tabular}{|c|c|c|c|c|c|c|c|c|c|c|c|c|c|}
\hline & & Dme & & D10\% & & & $\mathrm{D} 40 \%$ & D50\% & $0 \%$ & & $0 \%$ & & \\
\hline $\mathrm{Hon}$ & Min. & 1,30 & 1,86 & 1,51 & 1,40 & 1,34 & 1,30 & 1,27 & 1,24 & 1,20 & 1,16 & 1,12 & 1,03 \\
\hline hipp & $\mathrm{Ma}$ & 61,12 & 63,49 & 62,82 & 62,16 & 61,51 & 61,35 & 61,18 & 60,97 & 60,75 & 60,53 & 60,25 & \\
\hline & median & 53,8 & 59,99 & & & & 57,94 & 56,63 & 53,93 & 50 & 45,02 & 38,21 & 35,3 \\
\hline Con & Min. & 1,26 & $\begin{array}{r}1,99 \\
6107\end{array}$ & 1,52 & $\begin{array}{r}1,37 \\
5 f ? 2\end{array}$ & 1,31 & 1,27 & 1,23 & 1,10 & 0,94 & 0,83 & 0,73 & $\begin{array}{r}0,58 \\
2671\end{array}$ \\
\hline hipp & $\begin{array}{l}\text { Max. } \\
\text { median }\end{array}$ & \begin{tabular}{|l|}
46,88 \\
13,89 \\
\end{tabular} & $\begin{array}{l}61,07 \\
33,26\end{array}$ & \begin{tabular}{|l|}
58,33 \\
20,41 \\
\end{tabular} & $\begin{array}{l}56,23 \\
16,42 \\
\end{array}$ & \begin{tabular}{|l|}
52,73 \\
14,57 \\
\end{tabular} & $\begin{array}{l}49,68 \\
11,50\end{array}$ & $\begin{array}{l}46,27 \\
11,15\end{array}$ & $\begin{array}{l}42,65 \\
10,87\end{array}$ & \begin{tabular}{|l}
40,35 \\
10,74
\end{tabular} & $\begin{array}{l}38,34 \\
10,60\end{array}$ & $\begin{array}{r}37,62 \\
9,72\end{array}$ & $\begin{array}{c}\frac{36,71}{3,80} \\
3,\end{array}$ \\
\hline
\end{tabular}

Table 3b: Median dose delivered to each hippocampus (homo- or contralateral) and according to the three groups stratified by $\mathrm{D}_{40 \%}$ in each hippocampus

\begin{tabular}{|c|c|c|c|c|c|c|c|c|c|c|c|c|c|c|}
\hline \multirow{7}{*}{\begin{tabular}{|l} 
Group \\
1
\end{tabular}} & \multirow{4}{*}{$\begin{array}{l}\text { Homolateral } \\
\text { hippocampus }\end{array}$} & & $\overline{\mathrm{Dm}}$ & D] & $\mathrm{D} 10 \%$ & $\mathrm{D} 20 \%$ & $\bar{D}$ & D4 & D50\% & $\mathrm{D} 60 \%$ & D70\% & $\mathrm{D} 80 \%$ & D90\% & $\mathrm{D} 100 \%$ \\
\hline & & Min. & 1,30 & 1,86 & 1,51 & 1,40 & 1,34 & 1,30 & 1,27 & 1,24 & 1,20 & 1,16 & 1,12 & 1,03 \\
\hline & & Max. & 5,06 & 17,63 & 8,47 & 7,39 & 6,02 & 5,06 & 4,41 & 3,91 & 3,58 & 3,27 & 2,98 & 1,71 \\
\hline & & median & 2,78 & 6,32 & 4,77 & 3,69 & 2,64 & 2,30 & 2,19 & 2,04 & 1,94 & 1,80 & 1,71 & 1,35 \\
\hline & \multirow{3}{*}{$\begin{array}{l}\text { Contralateral } \\
\text { hippocampus }\end{array}$} & Min. & 1,26 & 1,99 & 1,52 & 1,37 & 1,31 & 1,27 & 1,23 & 1,19 & 1,11 & 1,00 & 0,90 & 0,77 \\
\hline & & Max. & 4,80 & 13,12 & 6,97 & 5,77 & 5,20 & 4,74 & 4,36 & 4,08 & 3,81 & 3,52 & 3,22 & 1,05 \\
\hline & & median & 1,99 & 5,47 & 3,50 & 2,11 & 1,73 & 1,60 & 1,47 & 1,38 & 1,30 & 1,20 & 1,12 & 0,99 \\
\hline \multirow{6}{*}{$\begin{array}{l}\text { Group } \\
2\end{array}$} & \multirow{3}{*}{$\begin{array}{l}\text { Homolateral } \\
\text { hippocampus }\end{array}$} & Min. & 8,44 & 17,94 & 10,78 & 10,65 & 10,35 & 8,56 & 7,87 & 7,87 & 4,12 & 3,27 & 2,44 & 4,79 \\
\hline & & Max. & 59,96 & 61,83 & 61,08 & 60,93 & 60,78 & 60,56 & 60,32 & 60,32 & 59,72 & 59,22 & 58,88 & 54,03 \\
\hline & & median & 35,54 & 54,95 & 45,74 & 43,05 & 40,98 & 38,47 & 34,90 & 34,90 & 22,06 & 17,04 & 15,34 & 7,50 \\
\hline & \multirow{3}{*}{\begin{tabular}{|l|} 
Contralateral \\
hippocampus
\end{tabular}} & Min. & 3,28 & 11,30 & 5,31 & 3,56 & 3,15 & 2,25 & 1,31 & 1,10 & 0,94 & 0,83 & 0,73 & 0,58 \\
\hline & & Max. & 12,59 & 54,15 & 34,18 & 25,58 & 13,73 & 7,40 & 6,22 & 5,94 & 5,51 & 4,91 & 4,16 & 3,57 \\
\hline & & median & 611 & 21,06 & 10,17 & 7,43 & 6,59 & 514 & 4,70 & 3,30 & 3,11 & 2,94 & 2,75 & 2,46 \\
\hline \multirow{6}{*}{$\begin{array}{l}\text { Group } \\
3\end{array}$} & \multirow{3}{*}{$\begin{array}{l}\text { Homolateral } \\
\text { hippocampus }\end{array}$} & Min. & 17,6 & 25,00 & 21, & 20, & 19, & 18, & 17 & & 15 & 14 & 9, & 9, \\
\hline & & Max. & 61,12 & 63,49 & 62,8 & 62,16 & 61,5 & 61, & 61,18 & 60,97 & 60,75 & 60,53 & 60,25 & 59,65 \\
\hline & & median & & 60,77 & 60,18 & 59,72 & 59, & 59 , & 58,98 & 58,73 & 57,98 & 56,79 & 55,49 & 44,26 \\
\hline & \multirow{3}{*}{$\begin{array}{l}\text { Contralateral } \\
\text { hippocampus }\end{array}$} & Min. & 8,1 & 16,02 & & 11,42 & & 8,12 & & 4,61 & 3,6 & 2,80 & 2,21 & 2,31 \\
\hline & & Max. & 46,8 & 61,07 & 58,33 & 56,23 & 52,7 & 49,68 & 46,27 & 42,65 & 40,35 & 38,34 & 37,62 & 36,71 \\
\hline & & median & 19,57 & 38,32 & 29,4 & 23,58 & 19,40 & 18,52 & 17,95 & 17,31 & 16,08 & 15,47 & 14,53 & 13,96 \\
\hline
\end{tabular}

Table 4: Volume size changes according to hippocampi groups.

Table 4a: Slope values of the volume lost (VL, $\mathrm{mm}^{3} / \mathrm{Gy}$ ) or percentage of volume lost (L - \%/Gy) in each hippocampus (homo or contralateral to the tumor) and for the three groups stratified by D40\% in both hippocampi: In group 1 (G1: n=6), in both 
hippocampi, the $\mathrm{D}_{40 \%}$ was < $7.4 \mathrm{~Gy}$; in group $2(\mathrm{G} 2: \mathrm{n}=13)$, the $\mathrm{H}_{\text {contra }} \mathrm{D}_{40 \%}$ was $<7.4$ Gy; in group 3 (G3: $\mathrm{n}=30$ ), the $\mathrm{D}_{40 \%}$ for both hippocampi was > 7.4 Gy

\begin{tabular}{|l|c|c|c|c|c|}
\hline & \# of patients & \multicolumn{2}{|c|}{ Homolateral } & \multicolumn{2}{c|}{ Contralateral } \\
\hline & & VL $\left(\mathrm{mm}^{3} / \mathrm{Gy}\right)$ & $\% \mathrm{~L}(\% / \mathrm{Gy})$ & VL $\left(\mathrm{mm}^{3} / \mathrm{Gy}\right)$ & $\% \mathrm{~L}(\% / \mathrm{Gy})$ \\
\hline Group 1 & 6 & -124 & +1.5 & +172 & +4.0 \\
\hline Group 2 & 13 & -15 & -0.51 & +15 & +4.3 \\
\hline Group 3 & 30 & $-19,7$ & -0.04 & $-19,7$ & -0.52 \\
\hline
\end{tabular}

Table 4b: Slope values of volume lost: The volume lost (VL) or percentage of volume lost (\%L - \%/Gy) according to the dose for both hippocampi between the reference MRI (dosimetric MRI) and last MRI during follow-up

\begin{tabular}{|l|l|l|l|l|}
\hline & $\mathrm{D} 40 \%<=7.4 \mathrm{~Gy}$ & $7.4 \mathrm{~Gy}<\mathrm{D} 40 \%<=30 \mathrm{~Gy}$ & $30 \mathrm{~Gy}<\mathrm{D} 40 \%<=50 \mathrm{~Gy}$ & $\mathrm{D} 40 \%>50 \mathrm{~Gy}$ \\
\hline Slope VL & $+94.3 \mathrm{~mm}^{3} / \mathrm{Gy}$ & $-8.6 \mathrm{~mm}^{3} / \mathrm{Gy}$ & $-45.4 \mathrm{~mm}^{3} / \mathrm{Gy}$ & $-112.2 \mathrm{~mm}^{3} / \mathrm{Gy}$ \\
\hline Slope $\% \mathrm{~L}$ & $+2.7 \% / \mathrm{Gy}$ & $-0.44 \% / \mathrm{Gy}$ & $-1.13 \% / \mathrm{Gy}$ & $-5.55 \% / \mathrm{Gy}$ \\
\hline
\end{tabular}

\section{Supplementary Files}

This is a list of supplementary files associated with this preprint. Click to download.

- Hippocampusannex1RO.docx

- Hippocampusannex2RO.docx 